Article

\title{
Administrative Reforms in the Fourth Industrial Revolution: The Case of Blockchain Use
}

\author{
Seunghwan Myeong $1, *,+\infty$ and Yuseok Jung ${ }^{2,+}$ \\ 1 Department of Public Administration, Inha University, Nam-gu, Incheon 402-751, Korea \\ 2 Department of Global E-Governance, Inha University, Nam-gu, Incheon 402-751, Korea \\ * Correspondence: shmyeong@inha.ac.kr \\ $\dagger$ These authors contributed equally to this work.
}

Received: 11 June 2019; Accepted: 13 July 2019; Published: 22 July 2019

\begin{abstract}
The increasing interest in blockchain since the end of 2017 has induced many attempts to apply it to public sector administration. Blockchains have been shown to improve the levels of economic efficiency, security and decentralization in administration. This exploratory study examines the determinants of blockchain administration and their priorities through an analytic-hierarchy process (AHP) analysis. The priority ranking of internal factors was security, economic efficiency, and decentralization. The introduction of blockchains in the evolution of the current e-government to the future of convergent governments will be generalized through trial, error, and learning processes. As experienced both in the knowledge and information society and in the e-government development process, reforming government administration is not solely a technical problem. The study results suggest that future blockchain administration in the public sector be used in the field of e-voting to encourage citizen participation in the process of agenda-setting, to enhance the level of security and transparency of taxation, and to increase the level of equity. Blockchain technology can also be used to improve efficiency in the provision of individually oriented social welfare services. Its adoption via administrative reform may reduce the level of corruption in personnel management, recruitment, and procurement in public sector organizations.
\end{abstract}

Keywords: blockchain; future administration; administrative reform; trust; AHP analysis

\section{Introduction}

The very relevant fourth industrial revolution involves various attempts to utilize diverse next-generation technologies in a wide range of fields, such as the Internet of things (IoT), artificial intelligence (AI), big data, and blockchain technology. Of these, blockchain technology has attracted attention as the most important new technology, given its relationship to Bitcoin. In South Korea, personal investment in Bitcoin increased at the end of 2017, which afforded it a negative perception as a kind of speculation or gambling.

However, the principle of blockchain's core technology and various studies have been attempting to apply it to the prevention of hacking in various sectors. Related research includes studies of electronic voting systems using blockchain technology, studies exploring how to secure transparency using distributed storage technologies, and studies of how to use it to create efficient governance or communication [1-4].

These research trends are occurring worldwide. Since acquiring a basic understanding of blockchain $[5,6]$, researchers are conducting studies on how to apply it to the public sector management and policy-making process $[7,8]$.

Blockchain technology is gaining strong attention among the various technologies being developed because of its advantages in enhancing transparency and security and in distributing existing centralized 
information storage. Trust, which has remained under the control of people and organizations, is now ensured by computers and de-centralized mechanisms through a decentralized consensus protocol based on blockchain. Whereas the existing paradigm employs services related to transactions, possessions, storage, or searches based on trust in the central system, blockchain relies on trust in a small community. "Unbundling" refers to the unbundling of an object into several smaller parts. Mobile devices, internet connections, web technologies, social networking services (SNS), and information access have been developed for business and shopping [9].

At present, the issue of money and blockchain can involve simply the underlying technology of cryptography, such as Bitcoin, but it may have a tremendous impact on accelerating the decentralization of society as a whole. Bitcoin using blockchain technologies means that, while the centralized accounting system has traditionally been based on a strong degree of trust and the resulting power, the emergence of blockchain and the use of technology will weaken the concentration of centralized power due to decentralization and liberalization. Owing to the decentralization of blockchain will not be confined to the economic field. Although blockchain technology based on cryptography has already been developed, a blockchain can be utilized in other fields.

If blockchain technology is applied to state management, it might be possible to build more efficient and equitable systems. In Korea, Song Kyung-Jin, the director of the World Economic Institute, stated that, as polarization and inequality were some of the biggest global issues in 2018, we must improve efficiency in welfare administration and the delivery system by swiftly introducing blockchain technology.

Therefore, this exploratory study is trying to find the core value of blockchain and suggests its possible convergence with various administrative fields as well as directions for development, with the goal of predicting its potential contribution to society. The determinants of blockchain administration and their priorities are examined through an analytic hierarchical process analysis. Finally, the administrative reforms are discussed in relation to the policymaking process, transparency, and trust in government.

\section{Literature Review}

\subsection{Bitcoin, Blockchain and Sociology}

Blockchain, which is considered one of the most important parts of the fourth industrial revolution, is inherently diverse and valuable. It was selected as one of the "Top Ten Rising Technologies of 2016" at the World Economic Forum (WEF) 2016. It is a publicly known technology that acts as a public record in transactions using digital currencies, such as Bitcoin.

Bitcoin is a peer-to-peer electronic payment system that operates as an independent currency [10]. Bitcoin and blockchain represent not just the emergence of a new technology, but the drivers of various sociological changes. A historical sociology of the antecedents and discourse leading to Bitcoin reveals that the goal was never 'money' in the economic sense, but rather a solution to the technical puzzle of preventing opportunistic actors from double-spending digital 'coins,' as well as a fervent ideology surrounding online privacy and the infringement of individual rights in the digital age. Drawing from themes in science and technology studies, bitcoin and other 'crypto assets' are fully formed socio-technological assemblages that constitute new and important objects of social inquiry that must be understood beyond the myopic context of crypto-money [11]. Blockchains are also actor-network platforms that digitally and securely enhance the imaging and transfer of economic value. In practice, attaching nondigital values to the digital representations of owning the right to move data, various types of blockchain including a socio-technical architecture are supported by formalized digital exchanges such as transactions and accountants. Blockchains' dynamic evolution poses a challenge for researchers of social sciences because of their potential to redesign and define many of their conventional knowledges for institutional formations of economization relations [12]. 
The technical concept of blockchain has been clearly defined as a growing list of records, called blocks, that are linked using cryptography. Each block contains a cryptographic hash of the previous block, a timestamp, and transaction data (generally represented as a Merkle tree root hash) [13].

This study focuses on predicting the social-structural changes that might be expected to occur according to the structure of blockchain depicted in Figure 1. Before the introduction of blockchain, the centralized system was based on strong public trust, and the resulting concentration of power. However, owing to the appearance of blockchains and the use of technology, the field of blockchain use, excluding some sectors, predicts a weaker concentration of central power in the future due to decentralization and liberalization. Distributed information can prevent the monopolization of information, while distributed storage also helps prevent the cyber-hacking of centralized information.

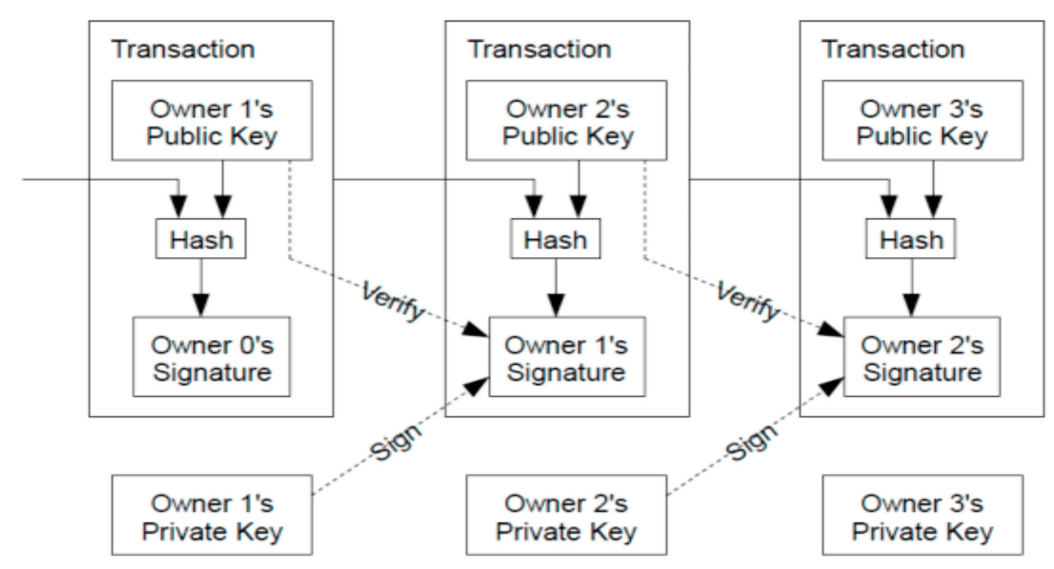

Figure 1. Blockchain Formation and Structure. By Researchgate (2017).

Identifying the potential change induced by blockchain to various paradigms is crucial. As a core technology of the fourth industrial revolution, it can be a driving force in economic growth, and can be used for development and innovation in various fields. In addition, it can enhance security by distributing information through distributed storage, thereby dispersing power, decentralizing paradigms, and preventing hacking. According to the 2018 book IITP Webzine, no central server has been the target of information leakage such as hacking. Malicious attackers have been hacking, but successfully hacking the blockchain system is regarded as virtually impossible Further, even if some participants' systems fail, the impact on the entire network is negligible due to the high system stability.

The goal of this study is to examine and predict the core technologies of blockchain and the value of its potential contribution to society.

\subsection{Blockchain Administration and Sustainability}

At present, the issue of money or blockchain may be simplified as the underlying technology of cryptography, such as Bitcoin, but it has the potential to greatly accelerate the sustainability of Bitcoin's administration, which uses block-chain technology, as a representative example of using distributed books, which dramatically improves transaction efficiency and security. These technologies are used not only in virtual money, but also in various fields such as society, administration, and politics as shown in Table 1.

The future of administration exceeds the simple process of delivering government services using blockchain technology. At present, attempts in various fields using blockchain have focused only on determining to where and which public sectors the technology can be applied, without any discussion of the sustainability of administration.

Before any application, the government in the world should discuss and define blockchain, justify its use, and determine its application. Furthermore, the crucial point is really necessary for sustaining the administration. After that, the government should increase emotional intelligence beyond the 
simple technology of blockchain and should cultivate diversity management ability based on such emotional intelligence.

Table 1. Cases of blockchain administration.

\begin{tabular}{|c|c|c|}
\hline Case & Title & Contents \\
\hline \multirow{2}{*}{ Korea } & DDABOK [14] & $\begin{array}{l}\text { Immediate results confirmation, introduction of } \\
\text { direct democracy }\end{array}$ \\
\hline & $\begin{array}{l}\text { Virtual currency in Gyeonggi-do } \\
\text { and Seoul [15] }\end{array}$ & $\begin{array}{l}\text { Prevention of external capital outflow for } \\
\text { local economy }\end{array}$ \\
\hline \multirow[b]{2}{*}{ The U.K. } & British Justice Department & $\begin{array}{l}\text { Saving Electronic evidence, process investigation, } \\
\text { security, securing }\end{array}$ \\
\hline & British Labor Department & $\begin{array}{c}\text { Efficiency of distribution of welfare allowance to } \\
\text { prevent illegal supply and demand of } \\
\text { welfare allowance }\end{array}$ \\
\hline \multirow[b]{2}{*}{ The U.S.A. } & $\begin{array}{l}\text { Health Information Technology } \\
\text { Bureau (ONC HIT) [16] }\end{array}$ & $\begin{array}{l}\text { Blockchain for secure integration and management of } \\
\text { health data }\end{array}$ \\
\hline & USPS Blockchain Platform [17] & $\begin{array}{l}\text { Electronic transfers without intermediaries, } \\
\text { providing customers with high speed and low cost, } \\
\text { solving security and accessibility problems }\end{array}$ \\
\hline Estonia & $\begin{array}{l}\text { Electronic Resident } \\
\text { Registration [18] }\end{array}$ & Electronic signature using blockchain technology \\
\hline Dubai & Blockchain Store System & $\begin{array}{l}\text { Electronic document recording and management } \\
\text { system without up and modulation }\end{array}$ \\
\hline Russia & Active Citizen & $\begin{array}{l}\text { Improve voter security vulnerabilities and ensure } \\
\text { transparency and credibility of voting results }\end{array}$ \\
\hline
\end{tabular}

Utilizing new technologies, including blockchain, will help overcome the limitations of current administrative services and supply sustainable administrative services to the people once again.

In this study, key factors of blockchain were extracted from various cases and weights were obtained through AHP questionnaire. It discussed the sociological implications of these factors and extended discussions to sustainable administration in the future.

\subsection{Main Factors in Blockchain}

Blockchain is a well-known technology that acts as a public record in transactions using digital currencies, such as Bitcoin. Blockchain technology has the potential to bring about fundamental changes in future markets and government functions [19].

The various advantages of blockchain technologies include their potential to enable e-voting. We conducted expert interviews and reviewed previous research to elicit factors that might generate strong, positive synergy in electronic voting.

\subsubsection{Economic Aspects}

Economics is the sense of rationality or the use of the economic principle that yields the greatest effect using the least means. Economic principles are based on the principles of maximum effect at a certain cost, of minimum cost for a certain effect, and of maximizing the difference between minimal cost and maximum effect. Although blockchain is seen as a simple development of economic growth, many attempts have been made to improve the efficiency of existing services and maximize the effects of lowering costs by applying blockchain technology. 
Innovative Processes

For example, in asset management, distributed ledgers are highly flexible; once implemented, they can be used to remove friction from the client onboarding process, streamline the management of model portfolios, speed the clearing and settlement of trades, and ease the burden of compliance associated with anti-money laundering and knowledge of customers. In addition, the market research firm IDC (International Data Corporation) predicted that banking costs would be reduced to $\$ 20$ billion by 2022. The WEF also predicts that by 2025, 10\% of the world's gross domestic product will come from blockchain platforms and transaction costs of financial companies will be reduced by 30\%. Many cases have been reported of decreased budget spending using blockchain technology processing as shown in Figure 2.

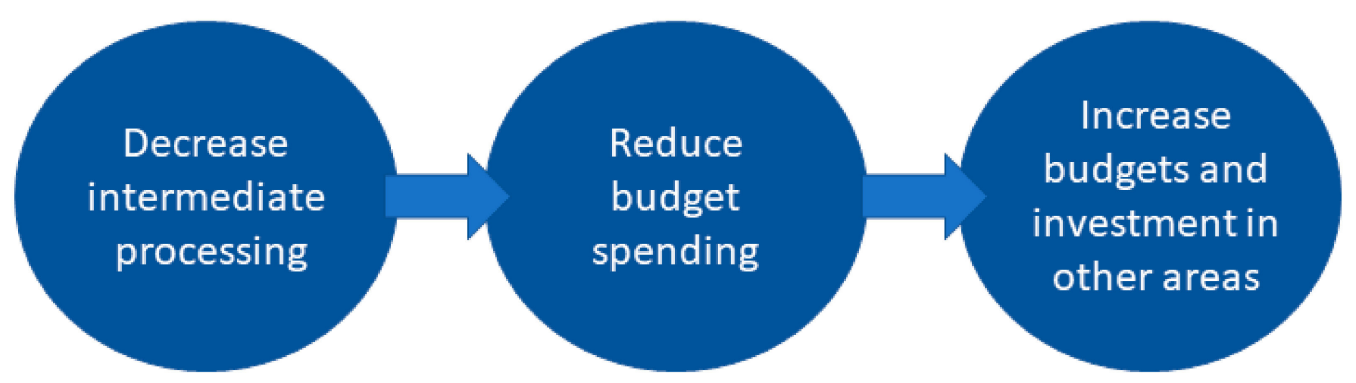

Figure 2. Innovative process and efficient use of budgets.

Universal Applications

Another advantage of blockchain is its wide applicability. Initially, blockchain began to attract public attention for its famous virtual currency. It has pioneered a new world where it is possible to purchase and sell products through existing cash money or an electronic card system and to use money in virtual space. A blockchain enables this economy via its role in improving transparency, security, and reliability.

In a modern society, blockchains can be used wherever transactions are established between parties. If blockchains are introduced in the medical field, the results of previous examinations can be registered in blockchain-based public books and, even if the prescription is not filled, the patient can receive the necessary medicine, or the same information can be obtained simultaneously without a separate process. One of the biggest advantages is that, because a blockchain system is distributed, and all blocks are stored in a distributed manner, the central storage system becomes unnecessary and the risk of hacking is reduced, which can significantly reduce security-related costs.

Among the many advantages of blockchain that have a wide range of general advantages, the most important in this study is its potential application to the public sector [20-22]. For example, offline polling places are no longer necessary and voting from home may become possible. Through blockchain electronic voting system, the contents and results of the voting process will be immediately encrypted and then forwarded to the election office. Such data can be disclosed to anyone in the world in real time. Many studies have examined and discussed the potential uses of blockchain in the public administration sector [23-25].

\subsubsection{Security}

The aforementioned factors illustrate economic efficiency and the nature of blockchain for new applications. However, it is the inherent security features that have focused attention on blockchain. Blockchain, as the name implies, is a chain of digital "blocks" that contain records of transactions; each block is connected to all blocks before and after it. This makes it difficult to tamper with a single record because a hacker would need to change the block containing that record as well as those linked to it to avoid detection. The distributed nature of the chain prevents tampering and revisions, as every 
action on blockchain is fully transparent. In turn, data that are stored in a blockchain can easily remain authentic because every transaction is recorded.

Hacking Prevention

The many studies attempting to maximize the security of blockchain include proposals for a security framework that integrates blockchain technology with smart devices to provide a secure communication platform in a smart city [26], with cloud computing [27], and with the IoT [23]. Innovative improvements in security through distributed storage are essential to blockchain. The data are decentralized, encrypted, and cross-checked by the whole network. Once a record is on the ledger, it is almost impossible to alter or remove it without it being noticed and the signature invalidated. Shared storage allows many people to share that security, which means that shared information is kept transparent. Improved transparency can prevent public information disclosure, the intervention of a third party, and information monopoly, and it is considered a key factor in the security advantages of blockchain, such as the prevention of hacking.

Decentralized Information

Blockchain is a storage platform that provides security and integrity; therefore, various services are utilizing these features to protect transaction information and facilitate copyright management. Banks and states have been producing and using blockchains and cryptocurrencies with unprecedented interest and resources, at a time when blockchains are presented as the historical instrument to undermine their power. The nodes participating in the network must have the same blockchain transaction data that are stored in the same block. Blockchain information is held by nodes participating in the network, and the same transaction history is distributed and managed. The hash value stored in each node is affected by the values of the previous blocks. It is difficult to manipulate registered contents once they are created. However, data hacking is possible if the majority of nodes are simultaneously hacked. However, this is impossible because hacking requires simultaneous operation and a supercomputer. As more people share, the reliability is improved, the process cost is dramatically reduced and blockchain utilizes the existing trust process to create security. The distribution of information in blockchain is a core value and fundamental principle of this technology.

\subsubsection{Decentralization}

Decentralization is one of the key factors ensuring the security of blockchain. Decentralization in terms of information security has brought about different paradigms in terms of politics and economics, while security has been improved through innovation by distributed storage of information. Decentralized information factors have been a topic of discussion in the information security field, but this section discusses the distribution of organizations and the relationship between organizations and decision making due to information dissemination. In addition, this study deals with the blockchain-induced changes to the philosophical and political paradigm.

\section{Dispersion}

Previous studies have focused on decentralized governance [28], organizations [29], economic policy [30,31], policy [32], etc. For example, a decentralized autonomous organization (DAO), sometimes labeled a decentralized autonomous corporation, is an organization represented by rules encoded as a computer program that is transparent, controlled by shareholders, and not influenced by a central government. This provides for a financial transaction record and program rules maintained on a blockchain, typified by the use of blockchain technology to provide a secure digital ledger to track financial interactions across the Internet and protect them from forgery by trusted time stamping and the dissemination of a distributed database.

As shown in Figure 3, Blockchains that can transparently share and store information are also a measure of information dissemination that stands in contrast to the monopoly of information by 
existing information monopolies. Currently, large search engine homepages such as Google and Yahoo monopolize information, and people have begun to question why information should belong to these companies.

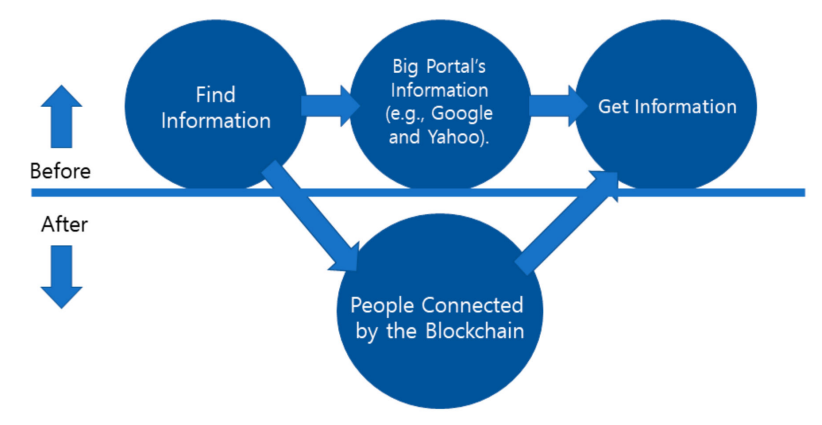

Figure 3. Dispersion by blockchain.

For example, without Google Scholar, many articles and studies cannot be found online due to Google's stranglehold on the monopoly of information. The search algorithm is designed so that the desired information can be retrieved only by retrieving a specific query. Algorithms seem to provide us with services, but in fact we must find the information in an algorithm that someone has already designed.

Blockchain technology does not require a central computer (server) to store and manage all information. As a result, the power that corporations and the government exercise over access to information is distributed to all users.

For this reason, blockchain is also called the "Cyberpunk" movement, which aims to democratize information. The application of blockchain technology can eliminate the huge information monopoly power of portal pages. It is also called "ownership of information," and blockchain will empower the owner of the information, rather than the provider of the information, to become the user.

\section{Decentralization Paradigm}

Companies' and governments' ability to monopolize information will be greatly reduced by the implementation of blockchain technology, leading to massive social changes. Blockchain technology aims to democratize information. Interest in decentralization through blockchain technology is constantly increasing in organizations, the political arena, and other areas of decision making, and it is creating new paradigms. As decision making based on blockchain increases and the minority of existing offline decision making is converted to a form in which the majority participates, power becomes dispersed, democracy is transformed, and direct democracy is more likely to be realized.

South Korea, in particular, suffers from an insufficient system of local autonomy. Although local entities are practically self-governing, they tend to rely on the central government for financial support. However, the emergence of blockchain has accelerated the paradigm for decentralization. The Korea Internet \& Security Association said that it is necessary to allow blockchain to play a role in establishing decentralization by introducing a preemptive policy through blockchain special zones. Furthermore, Cheung-Ju Si presented the plan entitled Help and Give Cheong-Ju, which is a blockchain local currency used by public institutions as local companies in the Cheong-Ju area collect coins from citizens and donors. The KT Blockchain Center in South Korea suggested that adding blockchain technology to the local online currency will enable seamless local currency services. Blockchain is expected to build a local economic ecosystem independently through virtual currency, to change the direction of local administration, to reinforce community through the implementation of direct democracy, and to become a technological cornerstone of the city. 


\section{Analytic-Hierarchy Process (AHP) Survey}

\subsection{AHP Survey}

Analytic-hierarchy process (AHP) analysis is a decision-making method developed to improve the efficiency of decision-making processes. AHP is a computational model designed by Professor Thomas L. Saaty that focuses on the brain's utilization of a phased, or hierarchical, analysis process. AHP is the main method of decision making because it is an individual measurement method that can estimate the value scale through pair comparison and ranking [33]. AHP analysis can be used to evaluate various alternatives systematically, to guide the weight to a percentage scale that reflects weight, and to classify the importance of the factors hierarchically so that better decisions can be made [34]. AHP analyses have been used in various studies as a decision-based method for conducting research through the selection of key factors and weights. The Structure of the analytic-hierarchy process (AHP) process is shown in Figure 4.

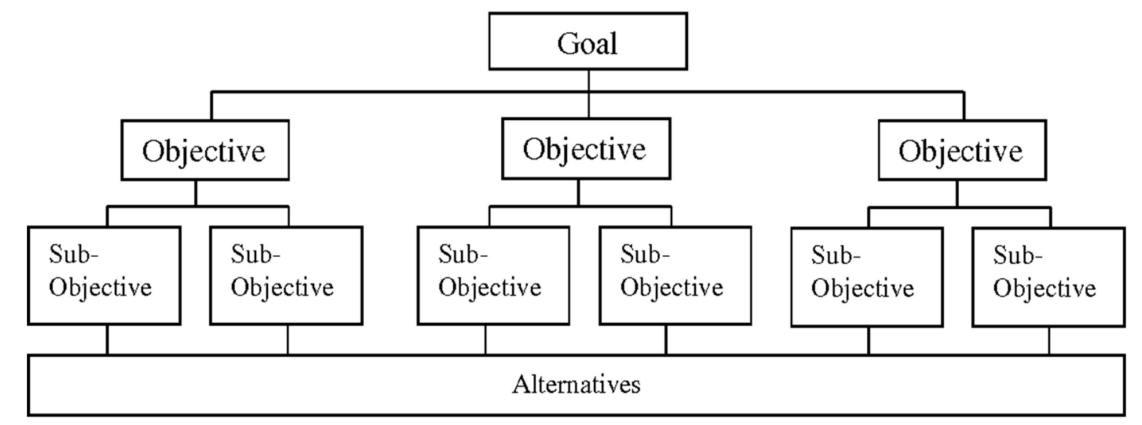

Figure 4. The Structure of the analytic-hierarchy process (AHP) process. Source: Razikin, M.A.M., and Halim [35].

\section{Data Collection and Expert Survey}

With the help of the Korea Policy Institute, questionnaires were distributed randomly via e-mail to about 600 professors and researchers of the Korea Policy Institute on 1 October 2018. Twenty-four questionnaires received by 8 October 2018 were analyzed. SPSS (Statistical Package for the Social Sciences) software (IBM, Armonk, NY, USA) was used to analyze the demographics of the respondents. The results are shown in Table 2.

AHP surveys were conducted with experts in the field. The AHP questionnaire contained a description of its specific characteristics as well as the concepts to be measured to determine their relative importance. The sample was also selected for experts who could understand the concepts. Unlike general surveys, the AHP survey method is considered not to require a large sample size [36]. This study was also analyzed on the basis of questionnaires with consistent answers and evidence of expertise.

It was necessary to have a group with practical knowledge and professional experience in collecting data for the AHP analysis application. A small group of 10 or fewer participants is acceptable in the case of homogeneous characteristics among group members [37].

Since group selection has a direct impact on decision-making outcomes, it was not necessary to select more than 30 samples for AHP because the error term of the AHP model does not follow the normal distribution. The robustness of the weight is increased by reducing the variance of the variance rather than the accuracy of the weight $[38,39]$. 
Table 2. Demographics of Respondents.

\begin{tabular}{|c|c|c|c|c|}
\hline \multicolumn{5}{|c|}{ Ages } \\
\hline & Frequency & Percent & Effective Percent & Cumulative Percent \\
\hline $20 \mathrm{~s}$ & 2 & 8.3 & 8.3 & 8.3 \\
\hline $30 \mathrm{~s}$ & 4 & 16.7 & 16.7 & 25.0 \\
\hline $40 \mathrm{~s}$ & 9 & 37.5 & 37.5 & 62.5 \\
\hline Over 50s & 9 & 37.5 & 37.5 & 100.0 \\
\hline Total & 24 & 100.0 & 100.0 & \\
\hline \multicolumn{5}{|c|}{ Occupation } \\
\hline & Frequency & Percent & Effective Percent & Cumulative Percent \\
\hline Public official & 1 & 4.2 & 4.2 & 4.2 \\
\hline Researcher & 12 & 50.0 & 50.0 & 54.2 \\
\hline Business & 4 & 16.7 & 16.7 & 70.8 \\
\hline Other & 3 & 12.5 & 12.5 & 83.3 \\
\hline 5.00 & 4 & 16.7 & 16.7 & 100.0 \\
\hline Total & 24 & 100.0 & 100.0 & \\
\hline \multicolumn{5}{|c|}{ Major } \\
\hline & Frequency & Percent & Effective Percent & Cumulative Percent \\
\hline Natural Science & 0 & 0 & 0 & 0 \\
\hline Social Science & 12 & 50.0 & 50.0 & 50.0 \\
\hline Humanities & 7 & 29.2 & 29.2 & 79.2 \\
\hline Engineering & 4 & 16.7 & 16.7 & 95.8 \\
\hline Other & 1 & 4.2 & 4.2 & 100.0 \\
\hline Total & 24 & 100.0 & 100.0 & \\
\hline \multicolumn{5}{|c|}{ Education } \\
\hline & Frequency & Percent & Effective Percent & Cumulative Percent \\
\hline Bachelor's & 4 & 16.7 & 16.7 & 16.7 \\
\hline Master's & 14 & 58.3 & 58.3 & 75.0 \\
\hline Ph.D. Candidate & 4 & 16.7 & 16.7 & 91.7 \\
\hline Ph.D. & 2 & 8.3 & 8.3 & 100.0 \\
\hline Total & 24 & 100.0 & 100.0 & \\
\hline \multicolumn{5}{|c|}{ Career } \\
\hline & Frequency & Percent & Effective Percent & Cumulative Percent \\
\hline Under 5 Years & 3 & 12.5 & 12.5 & 12.5 \\
\hline 5-10 Years & 5 & 20.8 & 20.8 & 33.3 \\
\hline 11-20 Years & 8 & 33.3 & 33.3 & 66.7 \\
\hline 21-25 Years & 4 & 16.7 & 16.7 & 83.3 \\
\hline Over 25 Years & 4 & 16.7 & 16.7 & 100.0 \\
\hline Total & 24 & 100.0 & 100.0 & \\
\hline
\end{tabular}

The reliability analysis of the AHP can be analyzed by calculating the CR (Consistency Ratio) value. The CR value is a method of measuring the degree of error in the judgment and response 
of individual evaluators when analyzing the relative importance between the individual evaluation factors. The smaller the $C R$ value $(C R<0.1)$, the greater the consistency [40].

\subsection{Results}

Through the literature review, key elements of the future blockchain administration were extracted. The development of the administration using blockchain can be largely centered on three key elements: economic, security, and decentralization. Blockchain technology can be used to improve the efficiency of administration processing such as budgeting and communicating in various administrative fields such as banking, maintenance, and storing information. It is also possible to store decentralized information to prevent information monopolies utilizing the principle of distributed storage. Finally, the principle of decentralization of blockchain can lead to various changes such as politics, economy, and society in the centralized system. Based upon the AHP hierarchy in Figure 5, the AHP questionnaire was conducted and the results were analyzed as follows the Figures 6 and 7 and Tables 3 and 4 .

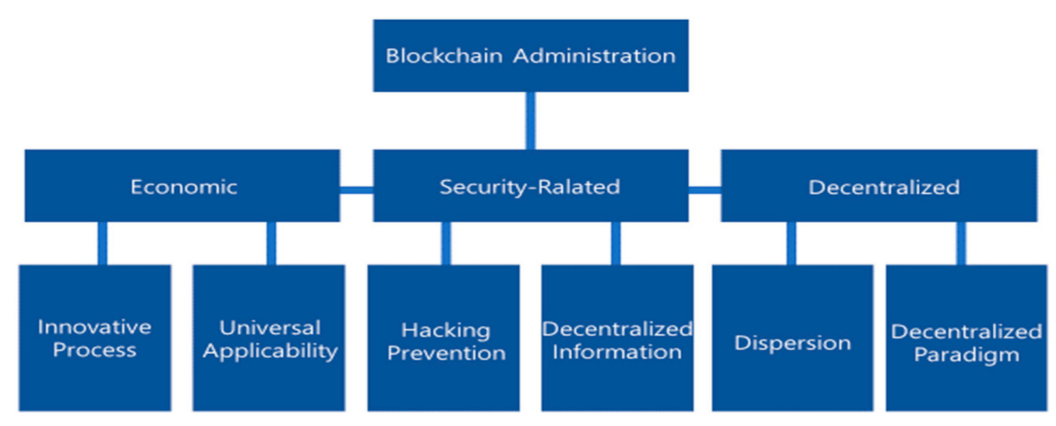

Figure 5. Blockchain administration AHP hierarchy.

Top Factors of Blockchain

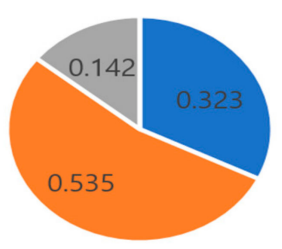

- Economic |- Security-Related |- Decentralized

Figure 6. Top factors in blockchain.
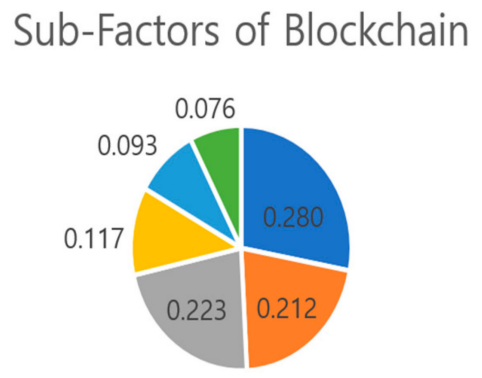

$$
\begin{array}{ll}
\text { - Innovative Process } & \text { - Universal Applicability } \text { - } \text { - Hacking prevention } \\
& \text { - Decentralized Paradigm }
\end{array}
$$

Figure 7. Sub-factors of blockchain. 
Table 3. The relative importance and priority of the main factors.

\begin{tabular}{ccc}
\hline Main Factors & Relative Importance & Priority \\
\hline Security-related & 0.535 & 1 \\
Economic & 0.323 & 2 \\
Decentralized & 0.142 & 3 \\
\hline
\end{tabular}

Consistency Index: 0.0002 .

Table 4. The relative importance and priority of the sub factors.

\begin{tabular}{ccc}
\hline Sub Factors & Relative Importance & Priority \\
\hline Innovative process & 0.280 & 1 \\
Hacking prevention & 0.223 & 2 \\
Universal applicability & 0.212 & 3 \\
Decentralized information & 0.117 & 4 \\
Dispersion & 0.093 & 5 \\
Decentralized paradigm & 0.076 & 6 \\
\hline
\end{tabular}

Consistency Index: 0.1006 .

As Figure 6 and Table 3 show, the exploratory study revealed that the security of the selected block sieve had the highest priority, at 0.535 , followed by economic priority at 0.323 , which did not greatly affect the security, and finally by the decentralization of blockchain at only 0.142 . The $C R$ value of the upper factor was 0.0002 , and this was considered evidence that the questionnaire was well-understood and answered.

As Figure 7 and Table 4 show, the AHP questionnaire on sub-factors also showed that CR values were relatively consistent (0.1006). However, as the sub-factor questionnaire was relatively difficult compared to the top-ranked factor, the $\mathrm{CR}$ value was higher than the $\mathrm{CR}$ value of the top factor.

The "Innovative process" factor, which is a sub-factor of security that was analyzed as a top priority as the result of the top-ranked factor, was classified as one of the six factors. "Hacking prevention," a sub-factor of economic efficiency, ranked second among the top-ranked factors, and second among sub-factors.

\subsection{The Relationship Between Blockchain Factors and Public Administration}

\subsubsection{Security Factors and Public Administration}

The AHP analysis supports the study prediction that the security of blockchain will be developed further by application to the field of administration. Other Korean studies have yielded similar results, namely, regarding CCTV (Closed Circuit Television) image management, product distribution, logistics management, vouchers, public institution certification, official document management, and history management. The security of blockchain is important in the management of advanced information or confidentiality, the storage and management of documents, the recent security of personnel management in Korea, and the protection of personal information. From a wider perspective, the Korean government's policy, which has recently been highlighted as its most extensive welfare policy in recent years, is to improve transparency through security as a way of managing welfare policy funds while preventing corruption and unnecessary recruitment; blockchain technology is expected to become a part of these efforts. The study result revealed that the security (0.535) of blockchain had the highest priority among the main factors, and the prevention of hacking $(0.223)$ had the second highest priority among the six sub-factors.

\subsubsection{Economic Factors and Public Administration}

The study result revealed the efficiency of blockchain as the second most important factor, after security. As described above, blockchain can minimize the intermediate process by avoiding storage of 
information in a central server and distributing it. In terms of security, budgets for existing security equipment can be drastically reduced, investments can be made elsewhere, economic advantages thereby created, and time costs can be reduced, all leading to increased overall efficiency.

As a representative example, an attempt has been made to perform power-trading based on the reliability of blockchain's transactions. With the fewer intermediate traders, an attempt has been made in the Brooklyn area of New York City to deal with the privately generated solar power generated by the blockchain system [41,42]. In the music recording industry, Imogen Heap, a well-known American singer, has sold record labels on a blockchain basis. In the United States, music distribution has traditionally been a monopoly. By using blockchain, it is now possible to access music consumers without the cost of intermediaries. In the financial industry, Goldman Sachs developed a blockchain-based securities trading system in 2015, which significantly reduced business hours by recording securities transactions in real time. Blockchain systems have also been used to establish a stolen-bicycle-reporting system in the Netherlands, a land registry system in Sweden, an electronic congress in Dubai and a food history system in China at IBM [43]. These attempts aim to overcome inefficient existing administrative systems by saving time and money while providing more satisfactory administrative services.

\subsubsection{Decentralization Factors and Public Administration}

As an important element of blockchain, decentralization was the subject of this AHP study. However, decentralization is also a very important factor by itself, despite having been assessed as less important than other, more realistic, practical factors. Security and economics are, in fact, important due to the decentralized distributed storage of blockchain.

Decentralization evokes the philosophy and paradigm of decentralization rather than the application of efficient practical research. Many researchers in the field of science and engineering are discussing how to apply blockchain technology to this area, and these studies are the primary focus. However, a philosophical examination of blockchain reveals a pivotal technology that humanist scholars, as well as researchers of politics, the economy, society, and administrations, need to incorporate into their research. The decentralization brought about by blockchain makes the individual's trust the central focus, rather than trust in a central server. Vitalik Buterin, founder of Etherium, attributed blockchain use to its facilitation of "censorship resistance" that cannot be implemented through the existing centralization method. He further emphasized that the essence of the blockchain platform is "decentralization" rather than "cost efficiency." Moreover, at 2018 Dispersive Economic Forum held in Seoul on August 4, he said that the reason for using blockchain is not to be efficient but to prevent censorship, fraud, and speculation, and to ensure interoperability and transparency, because it can prevent censorship and the intervention of central governments, banks, and other businesses.

Although the relative importance of decentralization in this study is lower than that of other factors, the implications of decentralization are significant. Blockchain may be a means to strengthen existing individual anti-corruption and interference measures as individual trust becomes stronger than trust in the center. If trust in the (formerly important) center collapses, there will be great turmoil in the world, and new social movements and massive organizational changes will result. In fact, in 2017, the leader of the centralized Korean government, Park Geun-hye, was impeached and a democratic regime change took place. The new government has a strong intention to utilize blockchains while promoting the decentralization of blockchain. While it may not be possible for blockchains to ensure complete decentralization, it is very clear that they will be used to mitigate centralization, as in the cases of DAO and blockchain electronic voting. This phenomenon is not accidental. Although the relative importance of this factor, decentralization, is lower than that of other factors, it is obvious that this is an important factor that should be considered by both academics and policy-makers. 


\section{Issues and Discussion}

\subsection{Government Trust and Blockchain}

The most important factor arising from the AHP survey is security. Utilizing the principle of distributed storage lowers the possibility of hacking and facilitates more transparent information management that will provide quickly accessible information to the public in real time. information and knowledge are important in the knowledge and information society It is very important to know how to use information efficiently and blockchain may assist in this process. With a high level of security, innovative information processing processes make it easy for people to access a variety of secure information. Utilization means accepting an objective object while actively and simultaneously responding to an objective object and producing new value [44]. The development of Information and Communication Technology (ICT) has contributed to the transparency and accountability of the government.

Therefore, through the active use of information, the government's control over the policy process and actions, or establishing a control system for the output and results, will ultimately affect government trust. In general, trust refers to the belief and will of the other party and his or her actions and intentions. There are two types of approaches to the concept of trust in the Ministry of Government Administration and Home Affairs. First, it is a type that describes general characteristics of trust. Trust is defined by taking into account the rights of others in the interchange $[45,46]$. Second, it is a type that specifically defines the meaning of trust. Trust is defined as the willingness to accept one's own vulnerability regardless of supervision or control in the context of expecting important behavior to the other $[47,48]$. Government trust is unilateral, as in the second type of trust, rather than reciprocal. This is because the government is subject to evaluation and the government does not evaluate the people. Myeong et al. [44] found that the public is able to search for information such as moral hazard and reverse choice problem agent through active information search. In theory, the government has more information than the public, so the government is in a better position than the mandate of the public. This asymmetry of information results from adverse selection and moral hazard. Consequently, this capability improves the level of confidence in the government. The introduction of blockchain greatly enhances the credibility of the government by securing procedural legitimacy through mutually oppressive transparent disclosure of information and rational choice.

\subsection{Administrative Transparency and Blockchain}

The transparency of administration is the ideology or oriented value of the government administration which dissolves the information asymmetry between the government and the public and expands the range of rational choice through the mutual sharing of information. International and non-governmental organizations are building a consensus that ICT can increase administrative transparency and reduce administrative corruption by blockchain. Particularly, the dispersiveness and reliability of blockchain technology can enhance the transparency of administration. However, transparency may differ from the expectation of public officials and citizens. In some situations, it may be perceived to be negative as opposed to positive. A higher level of transparency implies a lower level of discretion. The data held by the government are also accumulated by compulsory collection methods (information on residents by various reports), which may raise the dilemma of negating the purpose of protecting personal information due to transparent disclosure. In the governance system in which the relations of government, civilian and people are implemented in a balanced partnership relationship, equal transparency should be required not only for the government but also for the people, because of the need for mutual responsibility through mutual trust and rational containment.

E-government is not just an automated government with ICT, but a more value-oriented government that pursues ideology and values. Future smart e-government or intelligent convergence government will not change this value orientation. In view of the current tendency of information and means of national management to be distributed to individual civil society, a government that adopts 
blockchain technology needs greater capability for partnership that must produce entrepreneurial ability and mutual benefit for all. Internal corruption needs to be prevented by making the government transparent, the administration productive and efficient, and the government trustable. Blockchain enables all this. This raises questions about which attributes of blockchain can enhance administrative transparency. When the attributes of blockchain are considered as dispersiveness, security, and shareability, then administrative transparency is closely related to the dispersion, security, and sharing of blockchain. Especially, decentralization is a key attribute of blockchain that aims to open government and to establish a place for public opinion between government, business and citizens. Civility has the effect of facilitating the exchange of opinions by allowing easy access to the information held in the decision-making stage, improving the flexibility of the organization and making the decision-making process transparent and formalized. Security can realize the integrity of information, which allows information to be distorted and escaped from confinement by making it possible to establish a system to check duplication between government, business and citizens in decision making and enforcement. This ensures the efficiency, productivity, democracy, equity, and transparency of the administration, which have been regarded as mutually contradictory values, while simultaneously understanding the properties of blockchain and applying the advantages to the administration.

\subsection{Policy Decision-Making Process, Administrative Reform, and Blockchain}

In order to solve policy problem, the policy goal is set through the needs of the people and the policy formation process through the process of public debate. It is a decision process to adopt the desirable alternative as the policy by searching, comparing and evaluating the alternatives to achieve the set goal [49]. In order to set policy objectives, we need to thoroughly analyze the situation in which the policy problem lies, so that the policy problem can be correctly recognized. Second, information is needed to explore and analyze possible alternatives to achieve policy goals. ICT promotes communication and information access, which develops the core knowledge of the organization through the discovery and combination of knowledge [50]. Rational policy decisions are based on rational models. These make us explore all the information and alternatives available to the individual and chooses an action that maximizes the expected utility and profit through systematic analysis. However, even if ICT and information systems are advanced, it is almost impossible to select an optimal alternative by weighting all possible alternatives from a rational model perspective. For example, a policy decision cannot be made unless policymakers or policy participants intentionally conceal or share information in the process of analyzing or communicating information. The public sector decision making involves many stakeholders, including politicians, bureaucrats, social organizations, and interest groups, so that the gap between theory and reality brought about by rational policy decisions is larger than in the private sector. The problem of the information system that forms the basis of existing e-government is that the flow of information is cut off. The application of a blockchain system that shares knowledge among organizational members can be an alternative to overcome the limitations of this rational model.

On the other hand, administrative organizations are rigid because they are fundamentally bureaucratic and hierarchical and produce many procedures and regulations. Therefore, the introduction of e-government and administrative reforms, which did not fundamentally disappear from the bureaucracy, is difficult, and there is still a need for governmental structures that maintain regulatory universality, high corruption index, and behavior has not changed much. Administrative reform has two implications [51]. First, reform is the meaning of 'reality' that exists as an actual intangible type. Administrative reform in the substantive sense includes technical reform, administrative reform and policy reform. Second, reform is a process meaning as 'act'. Administrative reform in the process sense is a concept that focuses on the adaption and implementation process rather than the invention itself $[52,53]$. In other words, it means the reform of the process of linking policy decision and policy implementation. If administrative reform is redefined, it can be said that 'new ideas, management methods, strategies, and solutions' that enable members of the administrative 
organization to adapt to the environment and induce change. Therefore, blockchain can be the base technology and management method, strategy, and solution for the next generation convergence type e-government that can bypass the existing disconnection type e-government system and legal system. If a new convergence technology such as a blockchain can deviate from the path dependence of policy decisions that have traditionally been made in existing government structures and institutions, there is a good chance that a policy decision process close to the optimal model that overcomes limited rationality will be realized.

\subsection{Direction for Blockchain-Based Administrative Reform}

\subsubsection{Cases of Blockchain Application}

In South Korea, the most famous blockchain utilization service is local virtual money. By issuing local virtual currency for each administrative area, it is possible to reduce the card fee and to manage highly secure money. The currency is used to prevent outflow of money to the outside, and based on a simple charging system, the usage amount is over 21.49 million US dollars. This is because it is not necessary to provide commission to companies such as existing VISA (Visa Incorporated, San Francisco, CA, USA) and MASTER (Mastercard Incorporated, O'Fallon, MO, USA) card, so it is mainly used by small business owners and local government that have interests in developing local market keeps considering on application of the currency. This case is a representative example of providing high quality local administration service by improving the security and economic aspects of blockchain.

As shown in Figure 8 by Deusche Bank, blockchain technology has been being introducing to improve the processing time, procedures, and security of existing financial systems. This system eliminates the hassle of the existing system which guarantees the trust of the intermediary institution in the transactions such as inter-institutional remittance and settlement and improves the system to enable quick and simplified financial service with mutual trust. Application examples in finance will be applied to most financial services such as contracts, joint customer information management, remittance and settlement, bond issuance, and stock trading.

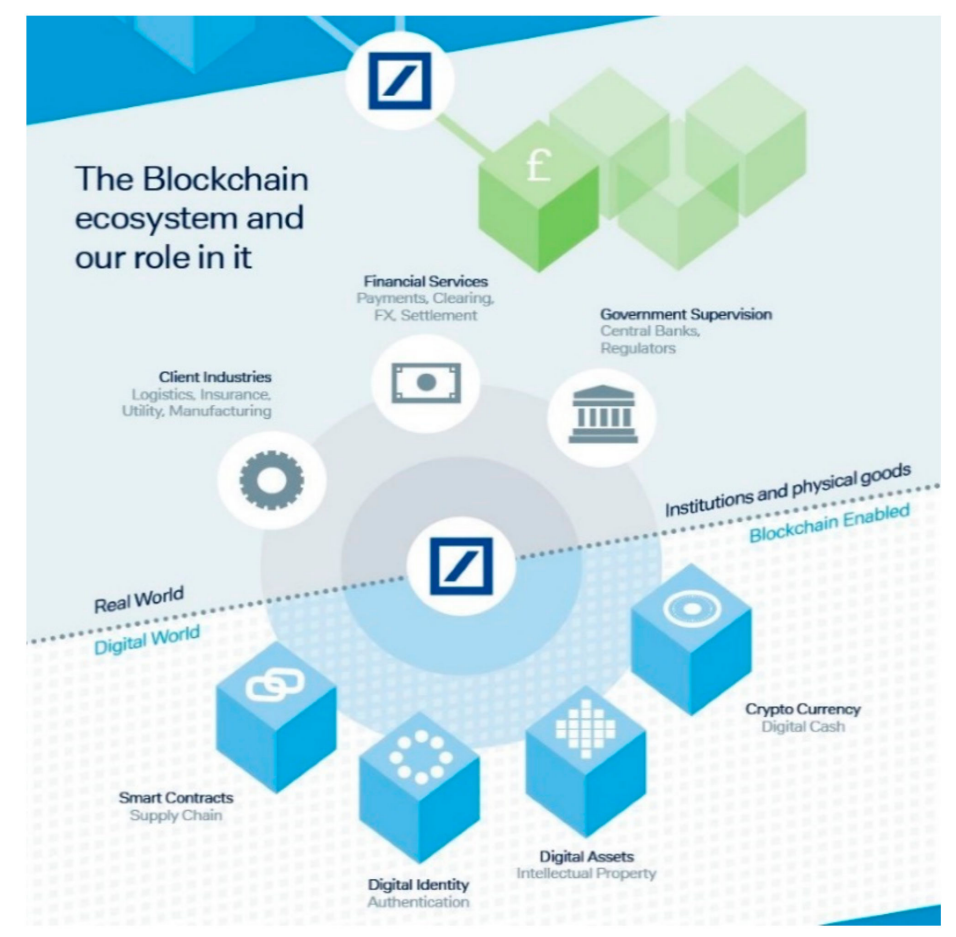

Figure 8. The blockchain ecosystem by Deusche Bank. 
It is expected to increase the administrative efficiency and the national convenience by improving the transparency and efficiency of the public sector and the cost reduction through the simplification of the administrative procedures and the quality of life of the people.

In many countries, the government has decided to adopt an active blockchain at the national level, and has been building a technological innovation environment by easing the barriers to the introduction of innovative technologies through pre-regulation or the introduction of regulatory sandboxes and strengthening government-private enterprise cooperation. In South Korea, local governments are relatively more active in introducing blockchain than central ones, such as local virtual currency, but it is imperative to develop related laws and systems for leading activation of the blockchain industry.

\subsubsection{Emotional Intelligence and Diversity Management Ability}

In the context of smart e-government, technology will be universal, but the complexity faced by governments or administrative agencies is often more social or emotional, rather than technical. For example, to manage relationships such as G2G (Government to Government), G2C (Government to Customer), G2B (Government to Business), and G2N (Government to Non-Profit; Interaction between government and NGOs), governance is essentially social-emotional. In the literature, socio-emotional intelligence is defined as the ability to absorb emotions into thinking, to emotionally understand and reason, and to control emotions of oneself and others [54]. Therefore, future administrative reforms should be viewed from the point of view of crossing blockchain technology to simple civil petitions and policy forums. It is necessary to provide detailed and differentiated blockchain services by establishing the relationships among the government-residents, residents-residents, and enterprises-residents in the local community by systematizing the sounds and issues of various classes.

Diversity is a concept that characterizes the paradigm shift from 'stovepiped' government to 'seamless' government [54]. The concept of diversity management is based on the idea that only a diversity can digest diversity [55].

It is very important for diversity management to establish behavioral diversity in the promotion of administrative reform. This is because behavioral diversity must be established to select the environment in which governments can cope $[56,57]$. Therefore, the government should raise the credibility of the government through diversity management, and it should become a representative model of 'smart government that can be predictable and reliable' by securing procedural legitimacy.

\subsubsection{Technical Aspects}

First of all, it is necessary to study the data storage and sharing method to handle the huge data produced in real time in blockchain networks. Standardization of blockchain technology that can be used internationally by the government and private sector is urgent. It is also necessary to confirm the security level of blockchain by securing the stability of blockchain authentication methods and comparing with the existing PKI (Public Key Infrastructure) based system. Blockchain is a technique for storing and managing a ledger in which information is recorded in a distributed manner on a peer-to-peer (P2P) network rather than in a central server. A bundle of transaction details is called a "block". It chains like a chain. Since data are shared, verified, and stored among participants through a network in the form of a hyper-distributed database, it is impossible to forge, modify, and manipulate them.

A trusted government will be the first step in administrative reform for those who are vulnerable to crime, such as phishing and hacking. In the event of a disaster, the intelligence of the state should not be lost or destroyed. The coexistence of the shield to keep information and the window to keep information is contradictory.

The future commercialization of quantum computing may render blockchain obsolete. Nevertheless, blockchain has many advantages such as transaction stability, cost reduction, transparency, and reliability because the deal is reached through the agreement of network participants, and it will be the most important smart e-government base until the emergence of another technological alternative. 


\subsection{Future Sustainable Administration with Blockchain}

Future administration would be a government that pursues both entrepreneurship and social values, the maximization of utilities, and the realization of both rational choice and social equity. Basically, a society without worry about eating, housing, commuting to the workplace, education, and medical care is a society that can foster individual self-realization and the pursuit of various values. Future administrative reforms should start from this point of view. With the transition from the industrial society to the information society, the government will be changed through the process of dialectical development between technology and society. The convergence of the government and the future is expected to play a role as a supporter to cooperate with the voluntary evolving social system and ecosystem in harmony with autonomy and control.

Table 5 summarizes the characteristics of technology such as blockchain, artificial intelligence, fusion technology, and the changes of civilization historical paradigm, decision making, and of decision-making mechanism.

Table 5. Changes of E-Government and future administration.

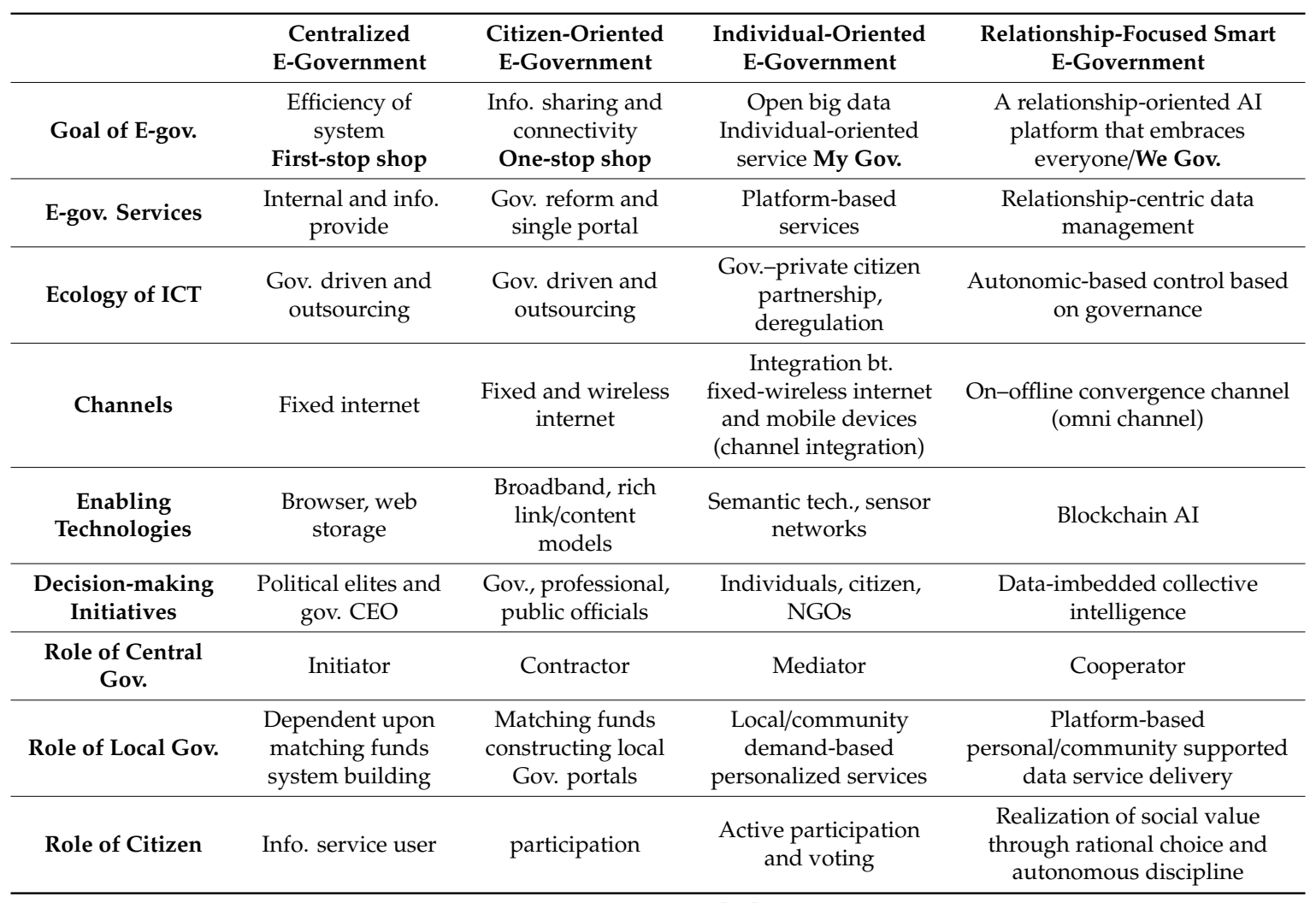

Source: Myeong [58].

As shown in Table 5, the future administration is more than a mechanical e-government working to improve productivity and transparency based on past computing systems. It is a platform that performs optimal policy decision and execution based on highly intelligent ICT and accurate data collection and analysis. However, the intelligent digital government, which is being proposed as the next generation of e-government along with the 4th industrial revolution, is a functional government based on computational intelligence with an emotionless algorithm. Future smart e-government will transcend the level of science as an artistic intelligence that grasps the minds and demands of the people and responds in a timely manner. Such a government will reach an artistic level where a system of ethical values, caring, and beliefs operates above a highly intelligent digital e-government. Blockchain technology is still unstable and numerous trials and errors are inevitable, but it has become a catalyst for 
triggering the transition to a new society that emphasizes relationships, and the birth of a predictable and reliable government based on rational choice and procedural legitimacy. It is foreseeable.

\section{Conclusions}

The possibilities for the future development of blockchain technology are unlimited. This study has selected the key factors of blockchain through AHP and discussed the possibility of blockchain administration and sustainability. Blockchain was applied to the field of administration to explore developments in future administrative processes as well. The importance of security, economics, and decentralization through AHP research was discussed. Furthermore, six sub-factors were analyzed for importance and the future blockchain administration and sustainability was discussed. Various overseas cases were explored using blockchain in various fields such as finance, decision making, information storage, and management.

E-government initiatives in Korea in the age of the "information society" have been quite successful and public-sector reforms have been instigated through e-government initiatives aimed at providing customer-oriented services based upon information management-oriented e-government. A "smart society" is highly pluralistic and people expect to receive timely information focused more on the interests of the general public than on those of the bureaucratic elite. This requires a new perspective on e-government that is based on smart technologies and instruments, including blockchain, big data analysis, and cloud computing, because the future public administration in a smart society will follow a more decentralized and transparent self-service model in a tightly engaged network and platform.

One of the limitations of research and future development is that most Korean experts are participating as technical experts, leading to regional limitations and difficulties in international generalization. Other research limitations include the limited value of certain aspects of the situation, whereas the potential applications to the field of administration are numerous and blockchain technology is continuously being developed. Many studies have focused on security and economic efficiency, while being applied to real-life contexts. Considerable research in science and technology is being carried out to provide new insight into the current international economic situation and new technologies. However, future studies on the decentralization of blockchain will also be needed to elucidate the philosophical ramifications of blockchain technology on politics, the economy, society, culture, and the humanities, as well as the social changes that this technology will create.

Based on the AHP results, this study suggests that future blockchain administration be used in the field of e-voting to encourage citizen participation in the process of agenda-setting, in enhancing the level of security and transparency for taxation, in increasing the equity and efficiency of the provision of individually oriented social welfare services, and in decreasing the level of corruption in areas such as personnel management, recruitment processes, and procurement in public sector organizations.

In this study, three top factors and six sub-factors of blockchain were selected through AHP via an exploratory study. Nevertheless, differences will arise in examining the key factors of blockchain, as they depend on the study purpose. These key factors cannot yet be generalized in the case of Korea. More comprehensive and reliable studies are needed to examine how to apply blockchain technologies to future administrative performance to achieve equally beneficial improvements at a lower cost.

Author Contributions: S.M. designed the research framework, wrote, and edited the paper; Y.J. conducted the survey, analyzed the data, and updated the literature review.

Funding: This work was supported by the Inha University in South Korea.

Conflicts of Interest: The authors declare no conflict of interest.

\section{References}

1. Kim, J.A.; Lee, H.J. Design and implementation of an electronic ballot system based on blockchain. In Proceedings of the Korea Information Science Society Conference, Seoul, Korea, 20-22 June 2018; pp. 1931-1933. 
2. Cho, H.S. Let's make a transparent and fair community with a blockchain. Local Inf. 2018, 111, 44-47.

3. Jin, J.H.; Go, G.J. Blockchain technology trends and health welfare information statistics. Health Welf. Forum 2018, 258, 96-106.

4. Lee, Y.H. Can blockchain technology create good governance? Implications of the Estonian case. J. World Area Stud. 2018, 36, 191-222.

5. Crosby, M.; Pattanayak, P.; Verma, S.; Kalyanaraman, V. Blockchain technology: Beyond bitcoin. Appl. Innov. 2016, 2, 6-10.

6. Pilkington, M. 11 Blockchain technologies: Principles and applications. Res. Handb. Digit. Transform. 2016, 225-253.

7. Gabison, G. Policy considerations for blockchain technology public and private applications. SMU Sci. Technol. Law Rev. 2016, 19, 327.

8. Novak, M. Crypto-Friendliness: Understanding Blockchain Public Policy. Available online: https://papers. ssrn.com/sol3/papers.cfm?abstract_id=3215629 (accessed on 19 July 2019).

9. Ryu, H.W. Business Blockchain: Decentralization Internet Technology Brings Business Innovation and Opportunity; Hanbit Publishing Network: Seoul, Korea, 2018; pp. 1-244.

10. Bjerg, O. How is Bitcoin Money? Theory Cult. Soc. 2016, 33, 53-72. [CrossRef]

11. Hayes, A. The Socio-Technological Lives of Bitcoin. Theory Cult. Soc. 2019, 36, 49-72. [CrossRef]

12. Caliskan, K. Data Money: The Socio-Technical Infrastructure of Cryptocurrency Blockchains. Available online: https://ssrn.com/abstract=3372015 (accessed on 15 November 2018).

13. Vigna, P.; Casey, M.J. The Age of Cryptocurrency: How Bitcoin and Blockchain Are Challenging the Global Economic Order; St. Martin's Press: New York, NY, USA, 2016; ISBN 9781250065636.

14. Choi, J.G.; Choi, J.S.; Yoon, S.E. Concept and direction of community in Gyeonggi-do. Policy Res. 2015, 1-145.

15. Choi, G.C. Local currency 'NW' using blockchain: Virtual currency that realizes social value such as volunteer and donation. Localization 2018, 111, 78-81.

16. Yue, X.; Wang, H.; Jin, D.; Li, M.; Jiang, W. Healthcare Data Gateways: Found Healthcare Intelligence on Blockchain With Novel Privacy Risk Control. J. Med. Syst. 2016, 40, 218. [CrossRef]

17. Kim, J.H. 4th Industrial Revolution and Foreign Friendship: US Postal Service (USPS) Block Chain Technology Review. Korea Communication and Telecom Policy. 2018, pp. 93-105. Available online: https:// www.kisdi.re.kr/kisdi/fp/kr/directory/selectResearch.do? cmd=fpSelectResearch\&curPage=1\&sSubjectNo= 0900\&sSubjectNo=0901\&controlNo=14198\&langdiv=1\&searchKey=\&searchValue=\&sSDate $=\&$ sEDate $=$ (accessed on 19 July 2019).

18. Sullivan, C.; Burger, E. E-residency and blockchain. Comput. Law Secur. Rev. 2017, 33, 470-481. [CrossRef]

19. Min, G.S.; Joo, Y.H.; Lee, S.H. Policy Proposal for the Development of Domestic Blockchain Industry; Korea Internet Promotion Agency: Seoul, Korea, 2018; pp. 1-15.

20. Park, Y.A.; Kim, J.H.; Kim, I.G. A Case Study of Electronic Ballot System Using Etherium Blockchain Technology. Inf. Technol. Res. 2017, 15, 201-218.

21. Wang, B.; Sun, J.; He, Y.; Pang, D.; Lu, N. Large-scale election based on blockchain. Procedia Comput. Sci. 2018, 129, 234-237. [CrossRef]

22. Kwon, K.J.; Kim, T.S. Implementation of electronic voting system based on private blockchain. Proc. Korean Inst. Commun. Sci. 2018, 600-610.

23. Huh, S.; Cho, S.; Kim, S. Managing IoT devices using blockchain platform. Advanced Communication Technology (ICACT). In Proceedings of the 19th International Conference, Bongpyeong, Korea, 19-22 February 2017.

24. Yu, J.M. Will blockchain lead to economic democratization? Future Horiz. 2017, 34, 22-25.

25. Mettler, M. Blockchain technology in healthcare: The revolution starts here. In Proceedings of the IEEE 18th International Conference on E-Health Networking, Applications and Services (Healthcom), Munich, Germany, 14-17 September 2016.

26. Biswas, K.; Muthukkumarasamy, V. Securing smart cities using blockchain technology. In 2016 IEEE 18 th International Conference on High Performance Computing and Communications; IEEE 14th International Conference on Smart City; IEEE 2nd International Conference on Data Science and Systems (HPCC/SmartCity/DSS), Munich, Germany, 14-17 September 2016; IEEE: Piscataway, NY, USA, 2016; pp. 1392-1393.

27. Park, J.H.; Jong, H.P. Blockchain security in cloud computing: Use cases, challenges, and solutions. Symmetry 2017, 9, 164. [CrossRef] 
28. Atzori, M. Blockchain technology and decentralized governance: Is the state still necessary? J. Governan. Regul. 2015, 6, 1-37. [CrossRef]

29. Chohan, U.W. The Decentralized Autonomous Organization and Governance Issues. Available online: https://ssrn.com/abstract=3082055orhttp://dx.doi.org/10.2139/ssrn.3082055 (accessed on 19 July 2019).

30. Garzik, J. Making Decentralized Economic Policy. 2015. Available online: https://www.phsz.ch/fileadmin/ autoren/videos/BIP100-blocksizechangeproposal.pdf (accessed on 19 July 2019).

31. Davidson, S.; De Filippi, P.; Potts, J. Economics of Blockchain. Available online: https://ssrn.com/abstract= 2744751 (accessed on 8 March 2016).

32. Miscione, G.; Kavanagh, D. Bitcoin and the Blockchain: A Coup D'État through Digital Heterotopia? Hum. Manag. Netw. 2015, 23/15, 1-27.

33. Saaty, T.L.; Mujgan, O. Negative priorities in the analytic hierarchy process. Math. Comput. Model. 2003, 37, 1063-1075. [CrossRef]

34. Saaty, T.L. The analytic hierarchy process: A new approach to deal with fuzziness in architecture. Archit. Sci. Rev. 1982, 25, 64-69. [CrossRef]

35. Razikin, M.A.M.; Isa, H. The use of analytical hierarchy process (AHP) in product development process. In Proceedings of the International Symposium on the Analytic Hierarchy Process, Kuala Lumpur, Malaysia, 23-26 June 2013.

36. Kwon, C.H.; Cho, G.T. A Study on the Selection of Non-Memory Semiconductor Chip Product Family Using AHP. Manag. Sci. 2001, 8, 1-13.

37. Lee, C.H. Collective Decision Making; Sejong Publishing Company: Seoul, Korea, 2000.

38. Lee, Y.H.; Cho, W.B.; Kim, S.H. A study on technology priorities for green highway. Int. J. Highw. Eng. 2012, 14, 151-162. [CrossRef]

39. Verly, C.; Karim, L.; De Smet, Y. An empirical analysis of elicited weights in AHP. In Proceedings of the 2010 IEEE International Conference on Industrial Engineering and Engineering Management, Macau, China, 7-10 December 2010.

40. Lee, J.G.; Nam, S.Y.; Jeon, H.J. Improvement of Advertising Industry Promotion Policy System after New Construction [is] Started; Korea Broadcast Advertising Promotion Corporation: Seoul, Korea, 2012; pp. 1-169.

41. Yoo, S.M. A study on smart grid trends and policy promotion plan. J. Korea Inf. Sci. Soc. 2014, 12, $163-177$.

42. Kastelein, R. Transactive grid: Blockchain technology power microgrid in Brooklyn. Blockchain News 2016, 1-5.

43. Lee, C.J. An Empirical Study on the Use of Information Technology and the Influencing Factors of Public Officials: A Comparison of Organizational Characteristics, Personality, and Technical Characteristics. Korean Gov. Scholarsh. 2010, 44, 221-260.

44. Myeong, S.H.; Lee, B.J. A study on elderly people's behavior for information use: Focusing on the elderly people's perception on information technologies. Korean J. Reg. Inf. Soc. 2010, 13, 23-47.

45. Cook, J.; Wall, T. New work attitude measures of trust, organizational commitment and personal need nonfulfillment. J. Occup. Psychol. 1980, 53, 39-52. [CrossRef]

46. Rotter, J.B. A new scale for the measurement of interpersonal trust. J. Personal. 1967, 35, 651-665. [CrossRef]

47. Boss, R.W. Trust and managerial problem solving revisited. Group Organ. Stud. 1978, 3, 331-342. [CrossRef]

48. Zand, D.E. Trust and managerial problem solving. Adm. Sci. Q. 1972, 17, 229-239. [CrossRef]

49. Her, B. Formation and Execution of Public Policy; Daeyoung Publisher: Seoul, Korea, 1988.

50. Bozeman, B.; Straussman, J.D. Managing Information strategically. In Public Management Strategies: Guidelines for Managerial Effectiveness; Jossey-Bass Publishers: San Franscio, CA, USA, 1991; pp. 108-134.

51. Mohr, L. Determinants of Innovation in Organizations. Am. Political Sci. Rev. 1969, 63, 111-126. [CrossRef]

52. Martin, L. A Model of Impacts of Advanced Information Technologies in Organizational Knowledge, Structure and Performance of Professional Service Firms; Working Paper; Stern School of Business, New York University: New York, NY, USA, 1944.

53. Zaltman, G.; Duncan, R.; Holbek, J. Innovations and Organizations; Wiley: New York, NY, USA, 1973.

54. Mayer, J.D.; Salovey, P.; Caruso, D. Models of emotional intelligence. In The Handbook of Intelligence; Sternberg, R.J., Ed.; Cambridge University Press: New York, NY, USA, 2000; pp. 396-420.

55. Beer, S. The Heart of Enterprise; John Wiley: Hoboken, NJ, USA, 1979.

56. Ashby, W.R. An Introduction to Cybernetics; Chapman \& Hall: London, UK, 1956. 
57. Schwaninger, M. Managing Complexity-The Path Toward Intelligent Organizations. Syst. Pract. Action Res. 2000, 13, 207-241. [CrossRef]

58. Myeong, S.H. A Study on the Paradigm Change of Gov3.0-Based E-Government Service with Smart Society Transition; Research Report; NIA (Korea Information Science Promotion Agency): Daegu, Korea, 2012.

(c)

(C) 2019 by the authors. Licensee MDPI, Basel, Switzerland. This article is an open access article distributed under the terms and conditions of the Creative Commons Attribution (CC BY) license (http://creativecommons.org/licenses/by/4.0/). 